\title{
Variation with socioeconomic status of indoor radon levels in Great Britain: The less affluent have less radon
}

DOI:

10.1016/j.jenvrad.2016.07.001

\section{Document Version}

Accepted author manuscript

Link to publication record in Manchester Research Explorer

\section{Citation for published version (APA):}

Kendall, G. M., Miles, J. C. H., Rees, D., Wakeford, R., Bunch, K. J., Vincent, T. J., \& Little, M. P. (2016). Variation with socioeconomic status of indoor radon levels in Great Britain: The less affluent have less radon. Journal of Environmental Radioactivity, 164, 84-90. https://doi.org/10.1016/j.jenvrad.2016.07.001

\section{Published in:}

Journal of Environmental Radioactivity

\section{Citing this paper}

Please note that where the full-text provided on Manchester Research Explorer is the Author Accepted Manuscript or Proof version this may differ from the final Published version. If citing, it is advised that you check and use the publisher's definitive version.

\section{General rights}

Copyright and moral rights for the publications made accessible in the Research Explorer are retained by the authors and/or other copyright owners and it is a condition of accessing publications that users recognise and abide by the legal requirements associated with these rights.

\section{Takedown policy}

If you believe that this document breaches copyright please refer to the University of Manchester's Takedown Procedures [http://man.ac.uk/04Y6Bo] or contact uml.scholarlycommunications@manchester.ac.uk providing relevant details, so we can investigate your claim.

\section{OPEN ACCESS}




\section{Variation with Socioeconomic Status of Indoor Radon Levels in Great Britain: the less affluent have less radon}

Gerald M Kendall $^{\mathrm{a}}{ }^{*}$, , Jon CH Miles ${ }^{\mathrm{b}}$, David Rees ${ }^{\mathrm{c}}$, Richard Wakeford ${ }^{\mathrm{d}}$, Kathryn J Bunch ${ }^{\mathrm{e}}$, Tim J Vincent ${ }^{\mathrm{f}}$, Mark P Little ${ }^{\mathrm{g}}$

a Cancer Epidemiology Unit, University of Oxford, Richard Doll Building, Old Road Campus, Headington, Oxford, OX3 7LF, UK.

b Formerly Centre for Radiation, Chemical and Environmental Hazards, Public Health England, Chilton, Didcot Oxon, OX11 0RQ, UK

c Centre for Radiation, Chemical and Environmental Hazards, Public Health England, Chilton, Didcot Oxon, OX11 0RQ, UK

d Centre for Occupational and Environmental Health, Institute of Population Health, The University of Manchester, Ellen Wilkinson Building, Oxford Road, Manchester, M13 9PL, UK e National Perinatal Epidemiology Unit, University of Oxford, Richard Doll Building, Old Road Campus, Headington, Oxford, OX3 7LF, UK

f Formerly Childhood Cancer Research Group, University of Oxford, New Richards Building, Old Road 12 Campus, Headington, Oxford, OX3 7LF, UK

g Radiation Epidemiology Branch, National Cancer Institute, DHHS, NIH, Division of Cancer Epidemiology and Genetics, Bethesda, Maryland 20852-7238, USA.

* To whom correspondence should be addressed email Gerald.Kendall@ceu.ox.ac.uk or Gerald.Kendall@Cantab.net tel $+44(0) 1865289600$

Running Title: Variation with SES of Indoor Radon Levels 


\begin{abstract}
We demonstrate a strong correlation between domestic radon levels and socio-economic status (SES) in Great Britain, so that radon levels in homes of people with lower SES are, on average, only about two thirds of those of the more affluent. This trend is apparent using small area measures of SES and also using individual social classes. The reasons for these differences are not known with certainty, but may be connected with greater underpressure in warmer and better-sealed dwellings. There is also a variation of indoor radon levels with the design of the house (detached, terraced, etc.). In part this is probably an effect of SES, but it appears to have other causes as well. Data from other countries are also reviewed, and broadly similar effects seen in the United States for SES, and in other European countries for detached vs other types of housing. With smoking, this tendency for the lower SES groups to experience lower radon levels may underlie the negative association between radon levels and lung cancer rates in a well-known ecological study based on US Counties. Those conducting epidemiological studies of radon should be alert for this effect and control adequately for SES.
\end{abstract}

Keywords: Radon, Socioeconomic Status, Deprivation, Epidemiology 


\section{Introduction}

The short-lived decay products of the naturally occurring radioactive gas radon (so-called radon progeny) are a known cause of lung cancer. Many epidemiological studies have been undertaken to explore this association in the context of domestic exposures, e.g. (Darby et al., 2005; Krewski et al., 2005; Lubin et al., 2004). Tobacco smoking is the main cause of lung cancer and it is important that proper account is taken of this factor in such investigations. The most informative studies have been of case-control design and included detailed information on smoking for the individual study subjects. However, a well-known ecological study reported a negative association between radon and lung cancer in US Counties (Cohen, 1995). Puskin (Puskin, 2003) found a similar inverse trend of cancer mortality with radon level in US Counties for other smoking-related cancers, but not for cancers unrelated to smoking. This strongly suggests that Cohen's observation was a result of confounding by smoking. Nevertheless, Cohen's paper (Cohen, 1995) is still cited, e.g. (Fornalski et al., 2015) (O’Connor and Calabrese, 2015), as evidence of relevance to radon risk.

Associations between childhood cancers and radon have also been investigated. Raaschou-Nielsen reviewed studies of indoor radon (Raaschou-Nielsen, 2008) and childhood leukemia and since that time other reports have been published, e.g. by Hauri et al (Hauri et al., 2013) and by Kendall et al. (Kendall et al., 2013b). However many such studies appear underpowered and no clear picture has yet emerged. There have also been reports associating radon with a variety of other cancers: Brain (Bräuner et al., 2013); Gastro-Intestinal Tract (Kjellberg and S., 1995); Central Nervous System (Del Risco Kollerud et al., 2014); Oesophagus (Ruano-Ravina et al., 2014); Prostate (Eatough and Henshaw, 1990) and Skin (Wheeler et al., 2012). Further investigations are required to confirm or otherwise these associations before any firm conclusions can be drawn. 
A recent paper reported a striking variation with socioeconomic status (SES) of indoor radon levels in Great Britain (GB: England, Wales and Scotland) (Kendall et al., 2015). Since the study was recordbased and did not involve direct contact with study subjects, response bias could not be a factor in this finding. Correlations of SES with indoor gamma-ray dose-rates were also investigated, but there were few effects (Kendall et al., 2015). Correlations between indoor radon concentrations and affluence have been reported in the past, in particular the UKCCS investigation of radon (UK Childhood Cancer Study Investigators, 2002), but have attracted little attention or discussion. It is the purpose of this paper to review these observations and to discuss the implications of, and possible reasons for, such variation.

As Galobardes et al. point out (Galobardes et al., 2006a) (Galobardes et al., 2006b), there is no single indicator of SES suitable for all study aims and applicable at all time points in all settings. Ideally, a number of separate parameters should be employed and recorded at successive points in the life-course of the study subjects. We discuss the parameters used in the present study in the following section, but in some of the work that we cite other indicators such as income or education are used. However, as Galobardes et al point out (Galobardes et al., 2006a) most of the indicators proposed are strongly correlated.

\section{Materials and methods}

\subsection{Sources of information}

Our main data source (Kendall et al., 2015) is an expanded dataset for a large record-based case-control study of naturally occurring radiation and childhood cancer in GB (Kendall et al., 2013b). This expanded dataset includes about 125,000 study subjects. Radon levels were estimated using over 400,000 measurements grouped according to geological boundaries (Miles and Appleton, 2005). We 
will refer to this study as the record-based case-control study or just case-control study where this is unambiguous.

The United Kingdom Childhood Cancer Study (UKCCS) (UK Childhood Cancer Study Investigators, $2000,2002)$ was a large interview-based case-control study of childhood cancer which studied, amongst other possible aetiological factors, radon gas. We will refer to this study as the UKCCS. Radon measurements were completed in 2226 case and 3773 control homes. The UKCCS investigators reported details of the variation of radon concentrations with SES for their controls which we re-analyse below.

We have also made use of the National Survey of exposure to natural radiation in UK Dwellings (Wrixon et al., 1988). This was smaller than the two epidemiological studies outlined above, covering 2093 UK homes, 2048 of which were in GB; the UK is GB plus Northern Ireland. However, the National Survey included information about the dwellings in question that was not available for the other datasets (see section 2.4).

Table 1 summarizes the data on variation of mean indoor radon concentration with SES from the expanded record-based case-control study (Kendall et al., 2015) and from the UKCCS (UK Childhood Cancer Study Investigators, 2002). We use two types of SES measure: those based on the characteristics of small geographical areas ("areal measures") and those based on the social class of a parent, derived from occupation. In order to simplify comparisons, we reanalyzed areal results for the record-based case-control study in seven categories (heptile 1 being the most affluent) to match the UKCCS data, and results for the two data sources are juxtaposed. Note, that the SES categories are similar but not identical in detail.

2.2 Measures of socioeconomic status 
The areal SES data used by the record-based case-control study were Carstairs Scores (Carstairs and Morris, 1991) (Carstairs and Morris, 1989) evaluated for electoral wards. Carstairs scores are based on

1) non-car ownership;

2) overcrowding in private households (more than one person per room).

3) male unemployment rates;

4) the proportion of households in which the head of the household is in social class 4 or 5 ;

These four variables are measured against the national average and re-scaled so that they have the same degree of variation across the country. The resulting transformed variables are given equal weight and combined to form an overall index of deprivation with higher levels indicating a higher level of disadvantage.

The areal SES data used by the UKCCS (UK Childhood Cancer Study Investigators, 2000) used an index developed by Draper et al (Draper et al., 1991) which predates the Carstairs index. In a broadly similar way to the Carstairs score it uses three measures of deprivation based on the 1991 census:

1. households without a car

2. overcrowded households (more than one person per room)

3. persons unemployed.

The two measures are thus similar, but not identical.

For both the record-based case-control study and the UKCCS the social class index used was derived from the occupation of a parent. Social classes run from 1 (likely to be most affluent) to 5 (likely to be least affluent). Social class 3 is divided into Non-Manual (3N) and Manual (3M) workers; 
additional background on the meaning of this parameter is given by Rose et al (Rose et al., 2005). For the case-control study the occupation of the father was taken; for the UKCCS the occupations of the parents resident with the child at the time of diagnosis were compared, the adult with the higher class taking priority. For the UKCCS occupation was determined at interview but for the case-control study it was derived from data on the birth record. The latter is self-reported without professional guidance and the data are incomplete (see section 4.1).

For the case-control study no social class could be assigned for 10341 (8.3\%) of fathers. The mean radon concentration for these individuals was $19.1 \mathrm{~Bq} \mathrm{~m}^{-3}$ compared to $22.0 \mathrm{~Bq} \mathrm{~m}{ }^{-3}$ for those for whom a social class could be assigned. For the UKCCS no social class could be assigned for 584 $(15.4 \%)$ of fathers; $21(0.6 \%)$ of these were in the Armed Forces. (For the case-control study if it was known that an individual was an officer they were assigned to social class 2 and other ranks to class $3 \mathrm{~N}$.) The mean radon concentration for those individuals for whom no social class was assigned in the UKCCS was 19.2 $\mathrm{Bq} \mathrm{m}^{-3}$ compared to $24.2 \mathrm{~Bq} \mathrm{~m}^{-3}$ for those for whom a social class could be assigned.

For the data of the case-control study the investigators reported that the correlation coefficient between Carstairs Quintile and occupational social class ( 6 categories) was $0.28(\mathrm{p}<0.001)$ based on 57 594 study subjects (Kendall et al., 2013a).

\subsection{Estimates of indoor radon concentrations}

For both areal SES and individual Social Class analyses, the radon estimates of the record-based case-control study are from a predictive radon map based on 400000 radon measurements grouped by geological and grid square boundaries (Miles and Appleton, 2005). The UKCCS radon estimates came from direct measurements using track-etch detectors in the houses in question (UK Childhood Cancer Study Investigators, 2002). The data for the UKCCS presented in table 1 are derived from geometric 
mean radon concentrations for controls given in Table 3 of the UKCCS radon paper (UK Childhood Cancer Study Investigators, 2002). The geometric means (GMs) were converted to the arithmetic means (AMs) used in the present paper by subtracting $3.8 \mathrm{~Bq} \mathrm{~m}^{-3}$, an estimate of the outdoor radon concentration (Gunby et al., 1993), and then assuming a geometric standard deviation of 0.948 (Miles, 1998). This procedure results in the GMs for the lowest and highest SES heptile converting to 27.2 and 16.1 $\mathrm{Bq} \mathrm{m}^{-3}$, respectively, the values cited by the UKCCS investigators (UK Childhood Cancer Study Investigators, 2002).

\subsection{Information on type of dwelling}

Information is not available on the type of dwelling (detached house, flat etc.) occupied by subjects in the record-based case-control study. However, this information is available for the measurements of the UK National Survey of natural radiation exposures in dwellings (Wrixon et al., 1988) and we make use of these data, augmented with estimates of the Carstairs deprivation score for the census ward in which each dwelling was situated based on data from the 1981 census. Wrixon et al presented data on radiation measurements in 2093 dwellings in the UK. In the present paper attention is restricted to the 2048 measurement sets for GB.

\section{Results}

Figure 1 and Table 1 demonstrate the reduction of mean radon concentration with lower areal SES (increasing deprivation) in the record-based case-control study and the UKCCS. Table 1 demonstrates a similar reduction of mean radon concentration with decrease in parent's social class.

Table 2 shows the number of measurements with mean indoor radon level and gamma-ray dose-rate by house type based on the data of the National Survey together with mean Carstairs score for the locations of these dwellings and Pearson product moment correlation coefficients between radon concentration 
and Carstairs score within house type and for the measurement set as a whole. Table 2 shows a broadly increasing radon concentration with increasing size of dwelling from $14 \mathrm{~Bq} \mathrm{~m}^{-3}$ in flats and maisonettes to $33 \mathrm{~Bq} \mathrm{~m}^{-3}$ in detached houses. Table 2 also shows that there is no such clear relationship of gammaray dose-rate with house type - gamma radiation dose-rate is slightly lower for flat/maisonettes and detached houses than for other house types.

Table 2 also shows the mean Carstairs deprivation score for each type of dwelling; the scores tend to be lower (and thus deprivation lower) in the dwellings with higher radon levels. The final columns of Table 2 show Pearson correlation coefficients between radon concentration and Carstairs deprivation score for the sample as a whole and within each house type. There is a highly significant $\left(\mathrm{p}<10^{-4}\right)$ negative correlation across the sample as a whole. For all categories of known house type there is also a negative correlation. However, these are far from similar in the strength of the statistical association. For semidetached/end-terrace houses the correlation coefficient is highly significant $\left(\mathrm{p}<10^{-4}\right)$ and for mid-terrace houses it is also significant $(\mathrm{p}=0.04)$, but it is not significant for the other two house types $(\mathrm{p}=0.38$ for detached houses and $\mathrm{p}=0.54$ for flats/maisonettes).

\section{Discussion}

\subsection{The National Survey of indoor natural radiation levels and other British data}

The first large-scale investigation of indoor levels of natural background radiation in the UK was the National Survey by Wrixon et al (Wrixon et al., 1988). Wrixon et al recorded the type of the dwelling in which measurements were made and reported that mean levels were higher in detached than in semidetached or terraced houses, which were in turn higher than flats or maisonettes. This finding was 
confirmed by Gunby et al (Gunby et al., 1993) in a more detailed re-analysis. Table 2 shows the data of the National Survey broken down by house type. One possible reason for detached houses having high levels is that they have more outside walls where leaky windows and wind-driven Bernoulli suction could increase the underpressure in the house leading to higher radon levels. However, the same argument would predict that semi-detached and end-terraced houses would have higher levels than midterraces and this is not seen. The conclusion would seem to be that the number of outside walls does not have a dominant effect. Of course it is clear that the observed gradient in radon levels with house type corresponds to a variation with levels of affluence and this is certainly likely to play a role.

However, Miles (Miles, 2001) examined the willingness of householders to agree to a radon measurement being undertaken. "Willingness to accept a measurement" was assessed as the number of invitations that were needed before a measurement was accepted. Even within a single house type, it was found that householders who were more willing to take a measurement had higher radon concentrations on average than those less willing. Generally speaking it is found that the more affluent are more likely to seek radon measurements. Miles speculated that one possible explanation for his observation might be relative poverty - poorer householders being less willing to take a measurement and also having lower radon levels. This is broadly supported by the correlations between radon concentration and Carstairs score within house type (Table 2) although the support is weak in the case of detached houses and flats/maisonettes.

Wolff and Wolff and Stern (Wolff, 1991a) (Wolff, 1991b, c; Wolff and Stern, 1991b) investigated the correlations between various measures of SES based on census data and mean radon concentrations for 22 counties in England and Wales. The radon data was from the National Survey (Wrixon et al., 1988). Despite the considerable averaging involved in analyzing geographical units as large as British counties (which have a mean population of the order of one million), Wrixon et al (Wrixon et al., 1988) 
reported considerable variation between the mean radon concentrations for different counties. The lowest mean concentration in the 22 counties considered by Wolff and Stern (Wolff and Stern, 1991a) was $10.4 \mathrm{~Bq} \mathrm{~m}^{-3}$ for mid-Glamorgan and the highest $119 \mathrm{~Bq} \mathrm{~m}^{-3}$ for Somerset. Wolff reported a number of correlations between lower affluence and lower radon levels. The most marked of these was for unemployment: $\mathrm{r}=-0.44, \mathrm{p}<0.025$.

Figure 1 shows a marked fall-off in indoor radon concentration with areal measure of SES from both the record-based case-control study and the UKCCS. The UKCCS suffered from a marked SESdependent variation in response rate (the less affluent being less likely to participate) (UK Childhood Cancer Study Investigators, 2000). The UKCCS investigators regarded this as a problem for their epidemiological analysis of childhood cancer and indoor radon concentration. However, it is unlikely to account for the variation of radon level with SES shown in figure 1. For both the record-based casecontrol and the UKCCS data the mean radon concentration in the most disadvantaged heptile is less than $60 \%$ of that in the most affluent (although we note that for the case-control data the radon concentration in the second most affluent heptile is, in fact, a little higher than that in the first).

For the UKCCS data, Table 1 shows a fall-off in mean indoor radon concentrations with increasing deprivation measured as (parental) social class, which is qualitatively similar to that for the areal measures of SES. However, the record-based case-control measure of (paternal) social class shows a far smaller variation with radon concentration, though the negative correlation is still highly significant $(\mathrm{p}<0.0001)$. For about $8 \%$ of the case-control study participants no social class could be assigned and these individuals tended to have lower indoor radon levels than other study participants. However, we believe that the problem is more likely to lie in the self-reported and uncontrolled nature of the father's stated occupation on the birth record. Of course in both the UKCCS and the case-control study, 
information on parental occupation was reported by the parent, but in the former case it was supplied under the guidance of a trained interviewer.

It is likely that more reliable and meaningful information on social class would be obtained by trained interviewers and this includes more reliable identification of unclassifiable individuals $(15 \%$ in the UKCCS compared to $8 \%$ in the case-control study, see Table 1). The case-control investigators (Kendall et al., 2013a) remark on the vagueness of some descriptions of occupations on birth records and the difficulty of assigning social class for paternal occupations such as "Engineer" without further information such as employment status and professional qualifications. Both the case-control study (Kendall et al., 2013b) and the UKCCS investigators (UK Childhood Cancer Study Investigators, 2002) preferred the areal index of SES for their main epidemiological analyses. The case-control study investigators remarked that, compared to national statistics, their study participants had a relative deficit of social class 2 with rather higher proportions in lower social classes - presumably more affluent individuals being wrongly assigned to lower social classes. Despite the shortcomings of the case-control study's social class data, they correlated very significantly with the Carstairs Quintiles data $(\mathrm{p}<0.0001)$. It should also be remembered that the occupation may have changed between the time of the birth of a child and the time of a diagnosis of cancer and that such changes are likely to be towards higher social classes.

\subsection{Data from other countries}

Casey et al (Casey et al., 2015) included SES as one of the factors considered in an investigation of predictors of indoor radon concentrations in Pennsylvania, USA. SES was estimated for communities from six variables from the US census. Radon levels were estimated from 866735 test results collected by the Bureau of Radiation Protection. Casey et al reported that communities with lower SES had lower 
radon levels. The trend was not monotonic with the highest radon levels being observed in the second quartile. Median radon levels for the fourth, most deprived, quartile were $78 \%$ (basements) and $71 \%$ (first floor) of those in the second quartile.

Cohen and Gromicko (Cohen and Gromicko, 1988) and Cohen (Cohen, 1991) investigated various factors affecting radon levels in US homes. One of the factors considered was annual family income. Those with incomes in the lowest quartile had lower radon levels, about $71 \%$ of that in the highest quartile and $74 \%$ of the overall mean, though the trend of radon concentration with income was not monotonic.

Several workers have investigated the factors affecting indoor radon concentrations or attempted to develop predictive models for radon concentrations in houses (Hauri et al., 2012) (Andersen et al., 2007) (Andersen et al., 2001) (Papaefthymiou et al., 2003) (Gerken et al., 2000) (Verger et al., 1994). These investigators were attempting to predict radon levels in particular dwellings, not for particular people. The models therefore did not include social class, nor did they discuss possible mechanisms for their findings. They have, however, generally confirmed the observation of Wrixon et al (Wrixon et al., 1988) that detached houses have higher radon levels.

\subsection{Summary and Interpretation}

Taking the data as a whole, we believe that there is strong evidence from Great Britain for a variation of indoor radon level with the SES of the household, less affluent homes having lower radon levels. This correlation is seen both for individual and small area estimates of SES and both for directly measured and for modelled radon concentrations. Broadly similar observations have been reported from the United States and from other countries. It is difficult to be certain whether similar associations might be seen in other countries or regions; the United Nations Scientific Committee on the Effects of Atomic 
Radiation (UNSCEAR) did not conduct such an analysis in its reviews of public exposure to radiation world-wide (UNSCEAR, 2008).

What might lie behind such an association? As noted in section 4.1, Miles (Miles, 2001) speculated that poorer householders might be less willing to accept a radon measurement and also have lower radon levels. This is broadly supported by the correlations reported in Table 2. A possible reason might be that poorer houses are not heated to the same level as wealthier households and/or that they have been less completely draught-proofed, for example by double-glazing. Both increased indoor temperature and draft-proofing will tend to increase the underpressure in the house relative to the air beneath the house and thus increase the rate at which soil gas is sucked into the house, resulting in higher radon levels. Gunby et al (Gunby et al., 1993) reported that double-glazing and draught-proofing were two significant factors in predicting higher indoor radon concentrations. So too was house type, which is likely to be correlated with SES. An explanation along these lines seems plausible.

\subsection{Implications for epidemiology}

The evidence presented here indicates that radon levels vary with SES. This observation may have implications for epidemiological investigations of links between indoor radon exposures and endpoints where disease rates vary with SES. As we argue below, we think this is of particular relevance to studies of indoor radon exposures and childhood cancer. In principle, problems should be avoided by, for example, stratification across SES categories. However, the strong variation of radon levels with SES reported here suggests that it may be important to ensure that such stratification is fine enough.

For example, in GB it is known that childhood leukemia rates vary with affluence (somewhat higher levels in more affluent families (Kroll et al., 2011)). The magnitudes of these variations due to SES are substantially greater than the expected variation due to radon exposure. Consequently, it is 
important to allow for SES in analyses of childhood cancer and indoor radon exposure. We note that it has been suggested that reported associations between SES and childhood leukaemia may be sensitive to the nature of the SES parameter chosen, to the study design and possibly to the calendar period (Poole et al., 2006) (Adam et al., 2008). This does not appear to be so in GB: Kroll et al (Kroll et al., 2011) found consistently higher levels of childhood leukaemia in more affluent areas over three decades, and Kendall et al (Kendall et al., 2013b) found very similar trends whether area-based or individual-based measures of SES were used. However, a full discussion of this question is beyond the scope of the present paper.

Smoking is an important factor in several cancers, most notably, lung cancer. Smoking rates vary with SES. The World Health Organisation report a tendency for the poorer to smoke more than those who are better off in most countries of all continents (Ciapponi, 2011). In particular, a number of studies have confirmed that lower SES groups smoke more heavily in the USA (Garrett et al., 2011; Jamal et al., 2015) and in Great Britain (Office for National Statistics, 2015). This pattern has also been confirmed for males in the European Union (EU) and for females in the North of the EU; however, for women in Southern Europe this trend is reversed (Mackenbach et al., 2007) (Mackenbach et al., 2008).

Stratification across SES may also be important for studies of radon and other endpoints where disease rates vary with SES. However, it is less likely to be relevant to studies of lung cancer where smoking is known to be the dominant causal factor: smoking rates do vary with SES but it is better and more direct to make careful allowance for smoking directly (Darby et al., 2005). In the study of Darby et al., the inclusion of social status affected the estimate of the excess relative risk of lung cancer when seven smoking categories were considered, but this was no longer the case when 20 smoking categories were considered (Darby et al., 2006). 
As noted in the Introduction, an ecological study reported a negative association between mean radon concentration and lung cancer mortality in US Counties (Cohen, 1995). Puskin (Puskin, 2003) (Puskin et al., 2004) found a similar inverse trend of cancer mortality with radon level in US Counties for other cancers related to smoking, but not for cancers unrelated to smoking, strongly suggesting that the observation of Cohen (Cohen, 1995) was a result of confounding by smoking. Cohen had attempted to allow for smoking (Cohen, 1995), but he could obtain data on smoking prevalence only at the level of the state, which he converted to the appropriate calendar period using national trends. He attempted to obtain estimates of smoking prevalence by county within state by allowing for the fraction of the county population that lived in urban areas. In fact, in the United States adults living in rural locations smoke more than those in urban (or suburban) areas (Vander Weg et al., 2011) and it is unclear how effective Cohen's attempted correction will have been. It is the failure to adequately account for correlations between cigarette smoking and radon levels within the sampling units that led to the spurious negative trends of lung cancer and radon of Cohen (Greenland and Robins, 1994); this correction Cohen did not attempt to implement, possibly because of the lack of necessary intra-sampling unit data, although such correction is in principle possible (Sheppard, 2003).

As discussed above, the less affluent tend to experience lower radon levels, at least in the United States and in Great Britain; in the United States (and in most other countries) they are also more likely to smoke. It is likely that these tendencies operate both between and within US Counties, the units considered by Cohen. Lower radon levels amongst those who tend to smoke more could provide a smoking-mediated mechanism which would account for the observations of Cohen (Cohen, 1995) and Puskin (Puskin, 2003) (Puskin et al., 2004) . 


\section{Conclusions}

There is evidence from Great Britain and the United States for a variation of indoor radon level with the SES of the household, less affluent homes having lower radon levels. This is of general environmental health significance and is a factor which should be considered in epidemiological studies of radon, particularly in relation to childhood cancers. Cohen reported a strong negative association between mean radon levels and lung cancer rates in US Counties (Cohen, 1995), but the study could not take proper account of smoking, which is likely to account for a large part of the effect that he observed, some of which may well be due to the inverse association between smoking and affluence. Since the less affluent are likely to experience lower indoor radon exposures, a smoking-based association between lower SES and lung cancer risk could account for the inverse relationship between lung cancer mortality and radon exposure reported by Cohen and also to the similar finding for other smoking related cancers by Puskin (2003). However, this association is largely mediated by the effects of cigarette smoking, rather than the causal effects of socioeconomic status per se.

\section{Acknowledgements}

The Childhood Cancer Research Group investigators were supported by Children with Cancer UK under grant number HTRVVK0. This work was supported by the Intramural Research Program of the National Institutes of Health, the National Cancer Institute, Division of Cancer Epidemiology and Genetics. The authors are grateful for the detailed and helpful comments of the three referees. RW does consultancy work, including for the UK Compensation Scheme for Radiation-linked Diseases. The authors declare that they otherwise have no actual or potential competing financial interests. 
We are grateful to Graham Smith for helpful discussions and to Claus Andersen for advice on radon levels in Denmark. 


\section{Reference List}

Adam, M., Rebholz, C.E., Egger, M., Zwahlen, M., Kuehni, C.E., 2008. Childhood leukaemia and socioeconomic status: what is the evidence? Radiat Prot Dosimetry 132, $246-254$.

Andersen, C.E., Raaschou-Nielsen, O., Andersen, H.P., Lind, M., Gravesen, P., Thomsen , B.L., Ulbak, K., 2007. Prediction of 222Rn In Danish Dwellings Using Geology And House Construction Information From Central Databases. Radiation Protection Dosimetry $123,83-94$. Andersen, C.E., Ulbak, K., Damkjær, A., Gravesen, P., 2001. Radon i danske boliger. Kortlægning af lands-, amts- og kommuneværdier. (translated title: Radon in Danish dwellings. Mapping of state, county and municipality values). . National Board of Health, National Institute of Radiation Hygiene, Copenhagan, Denmark, p. 132.

Bräuner, E.V., Andersen, Z.J., Andersen, C.E., Pedersen, C., Gravesen, P., Ulbak, K., Hertel, 0., Loft, S., Raaschou-Nielsen, 0., 2013. Residential Radon and Brain Tumour Incidence in a Danish Cohort. PLOS ONE 8, 1-7.

Carstairs, V., Morris, R., 1989. Deprivation, mortality and resource allocation. Community Medicine 11, 364-372.

Carstairs, V., Morris, R., 1991. Deprivation and Health in Scotland. Aberdeen University Press, Aberdeen.

Casey, J.A., Ogburn, E.L., Rasmussen S.G., Irving, J.K., Pollak, J., Locke, P.A., Schwartz, B.S., 2015. Predictors of Indoor Radon Concentrations in Pennsylvania, 1989-2013.

Environmental Health Perspectives 123, 1130-1137.

Ciapponi, A., 2011. Systematic review of the link between tobacco and poverty, in:

Ciapponi, A. (Ed.). World Health Organisation, Geneva, pp. 1-220.

Cohen, B.L., 1991. Variation of Radon Levels in U.S. Homes Correlated With House

Characteristics, Location, and Socioeconomic Factors. Health Physics 60, 631-642.

Cohen, B.L., 1995. Test of the Linear-No Threshold Theory of Radiation Carcinogenesis for

Inhaled Radon Decay Products. Health Physics 68, 157-174

Cohen, B.L., Gromicko, N., 1988. Variation of Radon Levels in U.S. Homes with Various

Factors. Journal of Air Pollution Control Association 38, 129-134.

Darby, S., Hill, D., Auvinen, A., Barros-Dios, J.M., Baysson, H., Bochicchio, F., Deo, H., Falk, R., Forastiere, F., Hakama, M., Heid, I., Kreienbrock, L., Kreuzer, M., Lagarde, F., Mäkeläinen, I., Muirhead, C., Oberaigner, W., Pershagen, G., Ruano-Ravina, A., Ruosteenoja, E., Rosario, A.S., Tirmarche, M., Tomásek, L., Whitley, E., Wichmann, H.E., Doll, R., 2005. Radon in homes and risk of lung cancer: collaborative analysis of individual data from 13 European case-control studies. BMJ 330, 223-227.

Darby, S., Hill, D., Deo, H., Auvinen, A., Barros-Dios, J.M., Baysson, H., Bochicchio, F., Falk, R., Farchi, S., Figueiras, A., Hakama, M., Heid, I., Hunter, N., Kreienbrock, L., Kreuzer, M., Lagarde, F., Mäkeläinen, I., Muirhead, C., Oberaigner, W., Pershagen, G., Ruosteenoja, E., Rosario, A.S., Tirmarche, M., Tomásek, L., Whitley, E., Wichmann, H.E., Doll, R., 2006. Residential radon and lung cancer - detailed results of a collaborative analysis of individual data on 7148 persons with lung cancer and 14,208 persons without lung cancer from 13 epidemiologic studies in Europe. Scand J Work Environ Health $32,1-83$. Del Risco Kollerud, R., Blaasaas, K.G., Claussen, B., 2014. Risk of leukaemia or cancer in the central nervous system among children living in an area with high indoor radon concentrations: results from a cohort study in Norway. Br J Cancer 111, 1413-1420. Draper, G.J., Vincent, T.J., O'Connor, C.M., Stiller, C.A., 1991. Socio-Economic factors and variations in incidence rates between county districts, in: Draper, G.J. (Ed.), The Geographical Epidemiology of Childhood Leukaemia and Non-Hodgkin Lymphomas in Great Britain 1966-83, OPCS Studies on Medical and Population Subjects No 53. HMSO, London, pp. $37-45$. Eatough, J.P., Henshaw, D.L., 1990. Radon and Prostate Cancer. Lancet 335, 1292. Fornalski, K.W., Adams, R., Allison, W., Corrice, L.E., Cuttler, J.M., Davey, C., Dobrzynski, L., Esposito, V.J., Feinendegen, L.E., Gomez, L.S., Lewis, P., Mahn, J., Miller, M.L., Pennington, C.W., Sacks, B., Sutou, S., Welsh, J.S., 2015. The assumption of radon-induced cancer risk. Cancer causes \& control : CCC 26, 1517-1518. 
Galobardes, B., Shaw, M., Lawlor, D.A., Lynch, J.W., 2006a. Indicators of socioeconomic position (part 1). Journal of Epidemiology and Community Health 60, 7-12.

Galobardes, B., Shaw, M., Lawlor, D.A., Lynch, J.W., 2006b. Indicators of socioeconomic position (part 2). Journal of Epidemiology and Community Health 60, 95-101.

Garrett, S.E., Dube, S.R., Trosclair, A., Caraballo, R.S., Pechacek, T.F., 2011. Cigarette Smoking - United States, 1965-2008. Morbidity and Mortality Weekly Reports (MMWR)

Supplements 60, 109-113.

Gerken, M., Kreienbrock, L., Wellmann, J., Kreuzer, M., Wichmann, H.E., 2000. Models for retrospective quantification of indoor radon exposure in case-control studies. Health Physics 78, 268-278.

Greenland, S., Robins, J., 1994. Ecologic Studies - Biases, Misconceptions, and Counterexamples. American Journal of Epidemiology 139, 747-760.

Gunby, J.A., Darby, S.C., Miles, J.C., Green, B.M., Cox, D.R., 1993. Factors affecting indoor radon concentrations in the United Kingdom. Health Phys 64, 2-12.

Hauri, D., Spycher, B., Huss, A., Zimmermann, F., Grotzer, M., von der Weid, N., Weber, D., Spoerri, A., Kuehni, C.E., Röösli, M., 2013. Domestic radon exposure and risk of childhood cancer: a prospective census-based cohort study. Environ Health Perspect 121, 1239-1244. Hauri, D.D., Huss, A., Zimmermann, F., Kuehni, C.E., Röösli, M., 2012. A prediction model for assessing residential radon concentration in Switzerland. J Environ Radioact 112, 8389.

Jamal, A., David M. Homa, D.M., O'Connor, E., Stephen D. Babb, S.D., Caraballo, R.S., Singh, T., Hu, S.S., King, B.A., 2015. Current Cigarette Smoking Among Adults - United States, 2005-2014. CDC Morbidity and Mortality Weekly Report 64, 1233-1240

Kendall, G.M., Bunch, K.J., Miles, J.C.H.M., Vincent, T.J., Little, M.P., Wakeford, R., Meara, J.R., Murphy, M.F.G., 2013a. Report of a record-based case-control study of natural background radiation and incidence of childhood cancer in Great Britain. Health Protection Agency, Chilton, Didcot.

Kendall, G.M., Little, M.P., Wakeford, R., Bunch, K.J., Miles, J.C.H., Vincent, T.J., Meara, J.R., Murphy, M.F., 2013b. A record-based case-control study of natural background radiation and the incidence of childhood leukaemia and other cancers in Great Britain during 1980-2006. Leukemia 27, 3-9.

Kendall, G.M., Wakeford, R., Bunch, K.J., Vincent, T.J., Little, M.P., 2015. Residential mobility and associated factors in relation to the assessment of exposure to naturally occurring radiation in studies of childhood cancer. J Radiol Prot 35, 835-868.

Kjellberg, S., S., W.J., 1995. The relationship of radon to gastrointestinal malignancies. American Surgeon 61, 822-825.

Krewski, D., Lubin, J.H., Zielinski, J.M., Alavanja, M., Catalan, V.S., Field, R.W., Klotz, J.B., Létourneau, E.G., Lynch, C.F., Lyon, J.I., Sandler, D.P., Schoenberg, J.B., Steck, D.J., Stolwijk, J.A., Weinberg, C., Wilcox, H.B., 2005. Residential radon and risk of lung cancer: a combined analysis of 7 North American case-control studies. Epidemiology 16, 137145 .

Kroll, M.E., Stiller, C.A., Murphy, M.F.G., Carpenter, L.M., 2011. Childhood leukaemia and socioeconomic status in England and Wales 1976-2005: evidence of higher incidence in relatively affluent communities persists over time. $\mathrm{Br}$ J Cancer 105, 1783-1787.

Lubin, J.H., Wang, Z.Y., Boice, J.D., Xu, Z.Y., Blot, W.J., De Wang, L., Kleinerman, R.A., 2004. Risk of lung cancer and residential radon in China: pooled results of two studies.

Int J Cancer 109, 132-137.

Mackenbach, J., Meerding, W.J., Kunst, A.E., 2007. Economic implications of Socio-economic inequalities in health in the European Union. European Communities, Luxembourgh.

Mackenbach, J.P., Stirbu, I., Roskam, A.J., Schaap, M.M., Menvielle, G., Leinsalu, M., Kunst, A.E., 2008. Socioeconomic inequalities in health in 22 European countries. The New England journal of medicine 358, 2468-2481.

Miles, J.C.H., 1998. Mapping radon-prone areas by lognormal modelling. Health Physics 74, $370-378$. 
Miles, J.C.H., 2001. Sources of bias in data for radon potential mapping. In: Proceedings of the Third Eurosymposium on Protection against Radon, Liege, May 10-11, 2001, Liege, pp. $175-177$.

Miles, J.C.H., Appleton, J.D., 2005. Mapping variation in radon potential both between and within geological units. J Radiol Prot 25, 257-276.

0'Connor, M.K., Calabrese, E.J., 2015. Response to Comments on 'Estimating Risks of Low Radiation Doses-A Critical Review of the BEIR VII Report and Its Use of the Linear NoThreshold (LNT) Hypothesis". Radiation Research 183, 481-484.

Office for National Statistics, 2015. Integrated Household Survey (Experimental statistics) January to December 2014, pp. 1-30.

Papaefthymiou, H., Mavroudis, A., Kritidis, P., 2003. Indoor radon levels and influencing factors in houses of Patras, Greece. Journal of Environmental Radioactivity 66, 247-260.

Poole, C., Greenland, S., Luetters, C., Kelsey, J.L., Mezei, G., 2006. Socioeconomic status and childhood leukaemia: a review. Int J Epidemiol 35, 370-384.

Puskin, J.S., 2003. Smoking as a Confounder in Ecologic Correlations of Cancer Mortality Rates with Average County Radon Levels. Health Physics 84, 526-532.

Puskin, J.S., James, A.C., Nelson, A.S., 2004. The Puskin observation on smoking as a confounder in ecologic correlations of cancer mortality rates with average county radon levels. Response to Cohen. Health Physics 86, 204-205.

Raaschou-Nielsen, 0., 2008. Indoor radon and childhood leukaemia. Radiat Prot Dosimetry $132,175-181$.

Rose, D., Pevalin, D., O’Reilly, K., 2005. The National Statistics Socio-economic

Classification: Origins, Development and Use. , London.

Ruano-Ravina, A., Aragones, N., Perez-Rios, M., Lopez-Abente, G., Barros-Dios, J.M., 2014.

Residential radon exposure and esophageal cancer. An ecological study from an area with high indoor radon concentration (Galicia, Spain). International journal of radiation biology 90, 299-305.

Sheppard, L., 2003. Insights on bias and information in group-level studies. Biostatistics $4,265-278$.

UK Childhood Cancer Study Investigators, 2000. The United Kingdom childhood cancer study: objectives, materials and methods. $\mathrm{Br} J$ Cancer 82, 1073-1102.

UK Childhood Cancer Study Investigators, 2002. The United Kingdom Childhood Cancer Study of exposure to domestic sources of ionising radiation: 1: radon gas. $\mathrm{Br} \mathrm{J}$ Cancer 86, 17211726.

UNSCEAR, 2008. United Nations Scientific Committee on the Effects of Atomic Radiation Report to the General Assembly, Volume 2 Effects of Ionising Radiation with Scientific Annexes. Annex E Sources-to-effects assessment for radon in homes and workplaces. . United nations, New York.

Vander Weg, M.W., Cunningham, C.L., Howren, M.B., Cai, X., 2011. Tobacco use and exposure in rural areas: Findings from the Behavioral Risk Factor Surveillance System. Addictive behaviors 36, 231-236.

Verger, P., Hubert, P., Cheron, S., Bonnefous, S., Bottard, S., Brenot, J., 1994. Use of field measurements in radon mapping in France. . Radiation Protection Dosimetry 56, 225 229.

Wheeler, B.W., Allen, J., Depledge, M.H., Curnow, A., 2012. Radon and skin cancer in southwest England: an ecologic study. Epidemiology 23, 44-52.

Wolff, S.P., 1991a. Leukaemia Risks and Radon. Nature 352, 288.

Wolff, S.P., 1991b. Radon and socioeconomic indicators. Lancet 337, 1476.

Wolff, S.P., 1991c. Radon and socioeconomic indicators - Correction to Lancet 3371476.

Lancet $338,326$.

Wolff, S.P., Stern, G., 1991a. Geographical associations between radon and cancer: Is domestic radon level a marker of socioeconomic status? J. Radiol. Prot. 11, 225-230. Wolff, S.P., Stern, G., 1991b. Geographical associations between radon and cancer: is domestic radon level a marker of socioeconomic status? J Radiol Prot 11, 225-230. 
Wrixon, A.D., Green, B.M.R., Lomas, P.R., Miles, J.C.H., Cliff, K.D., Francis, E.A., Driscoll, C.M.H., James, A.C., O'Riordan, M.C., 1988. NRPB-R190. Natural radiation exposure in UK dwellings. National Radiological Protection Board, Chilton, Didcot, Oxon. 
Table 1. Variation with Socio-Economic Status (SES) of mean indoor radon concentration

Two types of SES measure are shown: (a) those for small geographical areas ("areal estimates") and (b) for the social class of the father (case-control study) or parent of higher social class (UKCCS).

\begin{tabular}{|c|c|c|c|c|c|c|c|c|}
\hline (a) Heptile of areal estimates of SES & 1 & 2 & 3 & 4 & 5 & 6 & 7 & Total \\
\hline \multicolumn{9}{|c|}{ Case-Control data } \\
\hline Numbers of study subjects & 17780 & 17778 & 17783 & 17771 & 17757 & 17834 & 17751 & 124454 \\
\hline Mean indoor Rn Concentration $\left(\mathrm{Bq} \mathrm{m}^{-3}\right)$ & 24.7 & 26.3 & 25.0 & 23.0 & 21.2 & 18.3 & 13.6 & 21.7 \\
\hline Heptile mean as $\%$ of overall mean & 114 & 121 & 115 & 106 & 98 & 84 & 63 & 100 \\
\hline \multicolumn{9}{|c|}{ UKCCS Data } \\
\hline Number of measured controls & 686 & 688 & 656 & 594 & 463 & 390 & 296 & 3773 \\
\hline Mean indoor Rn Concentration (Bq m-3) & 27.2 & 26.8 & 25.5 & 25.5 & 21.4 & 20.4 & 16.1 & 24.2 \\
\hline Heptile mean as $\%$ of overall mean & 113 & 111 & 105 & 105 & 88 & 84 & 66 & 100 \\
\hline (b) Social class of parent & 1 & 2 & $3 \mathrm{~N}$ & $3 \mathrm{M}$ & 4 & 5 & & Total \\
\hline \multicolumn{9}{|c|}{ Case-Control data } \\
\hline Numbers of study subjects & 8193 & 25116 & 15379 & 39126 & 19291 & 7008 & & 114113 \\
\hline Mean indoor Rn Concentration (Bq m-3) & 22.0 & 22.8 & 22.2 & 21.7 & 21.8 & 20.6 & & 22.0 \\
\hline Category mean as $\%$ overall mean & 100 & 104 & 101 & 99 & 99 & 94 & & 100 \\
\hline \multicolumn{9}{|c|}{ UKCCS Data } \\
\hline
\end{tabular}




\begin{tabular}{|l|r|r|r|r|r|r|r|}
\hline Number of measured controls & 347 & 1222 & 639 & 642 & 279 & 60 & 3189 \\
\hline Mean indoor Rn Concentration (Bq m-3) & 29.4 & 26.2 & 23.9 & 22.7 & 23.1 & 18.4 & 24.2 \\
\hline Category mean as \% overall mean & 121 & 108 & 99 & 94 & 95 & 76 & 100 \\
\hline
\end{tabular}


Table 2. Radiation levels in various types of dwelling and Pearson product moment correlation coefficients between radon concentration and Carstairs score.

\begin{tabular}{|c|c|c|c|c|c|c|}
\hline & & & & & \multicolumn{2}{|c|}{$\begin{array}{l}\text { Correlations between } \\
\text { Carstairs score and } \\
\text { radon concentration }\end{array}$} \\
\hline Type of Residence & $\begin{array}{l}\text { Number of } \\
\text { dwellings }\end{array}$ & $\begin{array}{c}\text { Mean radon } \\
\text { concentration } \\
\mathrm{Bq} / \mathrm{m}^{3}\end{array}$ & $\begin{array}{c}\text { Mean gamma- } \\
\text { ray dose-rate } \\
\mathrm{nGy} / \mathrm{h}\end{array}$ & $\begin{array}{c}\text { Mean } \\
\text { Carstairs } \\
\text { Score } \\
\end{array}$ & $\begin{array}{l}\text { Pearson } \\
\text { Correlation } \\
\text { Coefficient } \\
\end{array}$ & $\mathrm{p}$-value \\
\hline Detached House & 511 & 33.2 & 89.7 & -1.22 & -0.04 & 0.38 \\
\hline $\begin{array}{l}\text { Semidetached or } \\
\text { end-terrace house }\end{array}$ & 807 & 19.3 & 98.7 & 0.13 & -0.15 & $<1 \mathrm{E}-4$ \\
\hline Mid-terrace house & 459 & 20.7 & 97.4 & 1.36 & -0.10 & 0.04 \\
\hline Flat/Maisonette & 250 & 13.9 & 85.9 & 2.16 & -0.04 & 0.54 \\
\hline Unknown type & 21 & 13.7 & 76.4 & 0.84 & 0.22 & 0.33 \\
\hline Total & 2048 & 22.4 & 94.4 & 0.32 & -0.10 & $<1 \mathrm{E}-4$ \\
\hline
\end{tabular}

Note: In their Table K4 Wrixon et al (1988) present broadly analogous data for the UK (rather than Great Britain) in which only dwellings with radon concentrations within twice the geometric standard deviation of the geometric mean were included. The effect of this censoring is to reduce the difference between house types. Wrixon et al also combined "semi-detached or end-terrace house" with "midterrace house". Wrixon et al did not have access to the Carstairs scores. 


\section{Figure caption}

Figure 1. Variation with areal socioeconomic status (SES) of mean radon concentration shown as percentage of the overall mean. Data are from the record-based case-control study and from the UKCCS. SES category 1 is the least deprived; category 7 the most.

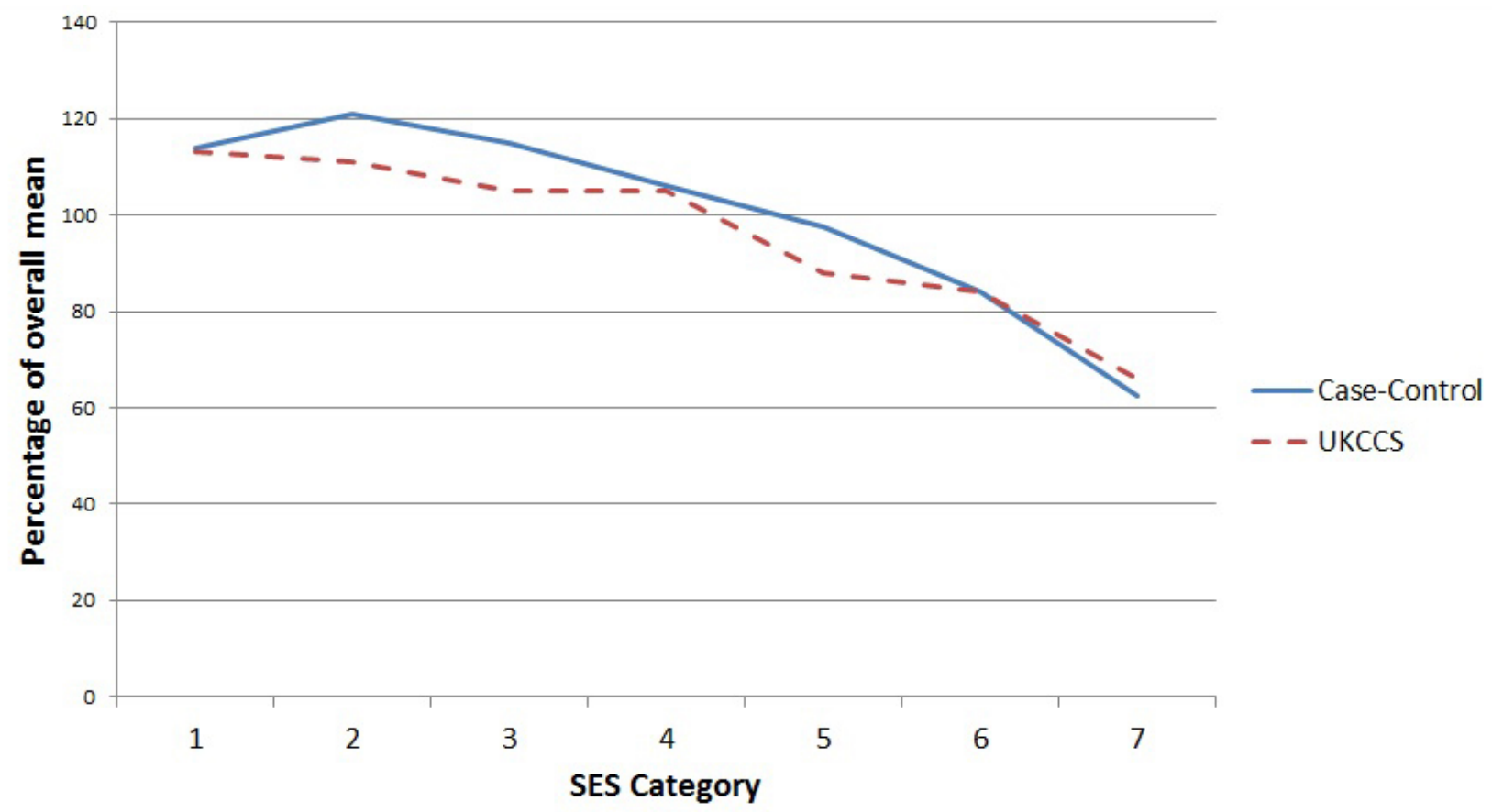

